\title{
Upper airway lengthening caused by weight increase in obstructive sleep apnea patients
}

Hongyi Lin ${ }^{1,2}$, Huahui Xiong ${ }^{1,2}$, Changjin $\mathrm{Ji}^{1,2}$, Cunting Wang ${ }^{1,2}$, Yong $\mathrm{Li}^{1,2}$, Yunqiang An ${ }^{1,2}$, Geng $\mathrm{Li}^{1,2}$, Jianggui Guo ${ }^{1,2}$, Xiaoqing Huang ${ }^{1,2}$, Han Zhang ${ }^{1,2}$, Hong Liu' ${ }^{1,2}$, Ting Li ${ }^{3}$, Zheng Li ${ }^{3}$, Junfang Xian ${ }^{3^{*}}$ and Yaqi Huang ${ }^{1,2^{*}}$ (D)

\begin{abstract}
Background: The longer upper airway is more collapsible during sleep. This study aims to reveal relationships among upper airway length, weight, and obstructive sleep apnea (OSA), particularly to answer why the upper airway of OSA patients is longer than that of healthy people and why some obese people suffer from OSA while others do not.

Methods: We perform head and neck MRI on male patients and controls, and measure $>20$ morphological parameters, including several never before investigated, to quantify the effect of weight change on upper airway length.

Results: The upper airway length is longer in patients and correlates strongly to body weight. Weight increase leads to significant fat infiltration in the tongue, causing the hyoid to move downward and lengthen the airway in patients. The apnea-hypopnea index (AHI) strongly correlates to airway length and tongue size. Surprisingly, a distance parameter $h$ and angle $\beta$ near the occipital bone both show significant differences between healthy males and patients due to their different head backward tilt angle, and strongly correlates with AHI. The contributions of downward hyoid movement and head tilt on airway lengthening are $67.4-80.5 \%$ and $19.5-32.6 \%$, respectively, in patients. The parapharyngeal fat pad also correlates strongly with AHI.

Conclusions: The findings in this study reveal that the amount of body weight and distribution of deposited fat both affect airway length, and therefore OSA. Fat distribution plays a larger impact than the amount of weight, and is a better predictor of who among obese people are more prone to OSA.
\end{abstract}

Keywords: Obstructive sleep apnea, Upper airway length, Body weight effect

\footnotetext{
*Correspondence: yqhuang@ccmu.edu.cn; cjr.xianjunfang@vip.163.com

'School of Biomedical Engineering, Capital Medical University, 10 Xitoutiao, Youanmenwai, Beijing 100069, China

${ }^{3}$ Department of Radiology, Beijing Tongren Hospital, Capital Medical

University, No 1 Dongjiaominxiang Street, Beijing 100730, China

Full list of author information is available at the end of the article
}

(c) The Author(s). 2020 Open Access This article is licensed under a Creative Commons Attribution 4.0 International License, which permits use, sharing, adaptation, distribution and reproduction in any medium or format, as long as you give appropriate credit to the original author(s) and the source, provide a link to the Creative Commons licence, and indicate if changes were made. The images or other third party material in this article are included in the article's Creative Commons licence, unless indicated otherwise in a credit line to the material. If material is not included in the article's Creative Commons licence and your intended use is not permitted by statutory regulation or exceeds the permitted use, you will need to obtain permission directly from the copyright holder. To view a copy of this licence, visit http://creativecommons.org/licenses/by/4.0/ The Creative Commons Public Domain Dedication waiver (http://creativecommons.org/publicdomain/zero/1.0/) applies to the data made available in this article, unless otherwise stated in a credit line to the data. 


\section{Introduction}

Obstructive sleep apnea (OSA) is characterized by repeated collapse and obstruction of the upper airway (UA) during sleep [1]. UA geometry has significant effect on airflow characters, resistance, and obstruction [2, 3]. Previous studies have revealed that a longer airway has a considerably less negative closing pressure and is therefore more collapsible [4]. Morphological measurements do show that UA in patients is significantly longer compared with normal subjects $[5,6]$. Studies also show a correlation between UA length and OSA severity $[7,8]$. However, the mechanism of UA lengthening in OSA patients is unclear.

Obesity has a strong correlation with OSA [9-13]. It is estimated that $58 \%$ of moderate to severe OSA is due to obesity [14]. Because of increased fat deposition, overweight and obese individuals generally have a larger tongue [10, $15,16]$ and more collapsible airway than normal-weight individuals [17-20]. From the observations that there is a high OSA prevalence in obese people and a long upper airway in many OSA patients, one may ask whether an increase in body weight can increase UA length, and therefore make UA more collapsible. There has currently not been any investigation focusing particularly on the relationship between UA length and weight change. A study observed that UA length decreased in OSA patients after 24 weeks of weight loss, but the reason remained unclear [21]. A quantitative investigation about the different effect of body weight on UA length between normal people and OSA patients may solve the puzzle: why do some people with obesity suffer from OSA while others do not?

In this study, we will test the hypothesis: both the amount of body weight and distributions of deposited fat in the head and neck can affect airway length, but the fat distribution dominates the change in UA length and determines who among obese people are more prone to OSA.

\section{Methods}

\section{Subjects}

Chinese male candidates were recruited through public notice boards and determined through overnight polysomnography monitoring. Eighteen patients with apnea-hypopnea index $(\mathrm{AHI})>15(\mathrm{AHI}=43.59 \pm 17.57)$, who may exhibit typical OSA characteristics, participated in this study. Twenty healthy subjects were selected by a careful evaluation based on their basic information and survey results. A qualified candidate should have no symptoms such as snoring, sleep apnea, and daytime somnolence. We also performed polysomnography tests for six candidates, $30 \%$ of all healthy subjects, to ensure that their $\mathrm{AHI}<5$. We did not match the body mass index (BMI) between the two groups in order to better observe the effect of weight on UA length in a larger BMI range. We also formed two BMI matching groups with weight $69-93 \mathrm{~kg}$, which could maximize the size of each group to include 14 OSA patients and 13 healthy subjects, to observe the similarities and differences in morphological parameters between OSA patients and healthy people with similar BMI. The data were analyzed with age as a covariate to account for the effect of age. Table 1 summarizes the characteristics of the subjects. Nobody had heart failure, renal failure, tonsillectomy, or uvulopalatopharyngoplasty. Nobody had been previously treated for OSA. The ethics committee of Capital Medical University approved the study (2013SY67), and all subjects signed the informed consent.

\section{Magnetic resonance imaging (MRI)}

Using a spoiled gradient echo sequence described in details in the references [22-24], we performed axial and sagittal scanning in a $3.0 \mathrm{~T}$ MRI scanner (Signa HDxt, General Electric, USA) to obtain images from the nasal cavity to the laryngeal prominence. Subjects were awake and lying supine. They were told not to swallow during scanning. Because obese people had a larger head backward tilt angle when lying supine than subjects with normal weight, in order to observe the effect of head tilt angle on UA geometry, we also performed MRI under three states: lying supine, with partial chin elevation, and with a maximum chin elevation in healthy subjects.

\section{Reconstruction of tissue structures and measurement of morphological parameters}

We segmented tissues from the images manually, reconstructed the three-dimensional structures of UA, tongue, fats in the mandibular space and parapharyngeal space, fat behind the neck, and posterior cervical soft tissue using Mimics (Materialise Inc., Leuven, Belgium), and measured their morphological parameters including the tissue volume, crosssectional area, length, angle, and relative positions. Figure 1 diagrams some of the tissues measured in this study.

Table 1 Characteristics of male OSA patients and healthy subjects

\begin{tabular}{|c|c|c|c|c|c|c|}
\hline & \multicolumn{3}{|l|}{ No BMI matching } & \multicolumn{3}{|l|}{ BMI matching } \\
\hline & OSA patients $(n=18)$ & Healthy subjects $(n=20)$ & $P$ value & OSA patients $(n=14)$ & Healthy subjects $(n=13)$ & $P$ value ${ }^{*}$ \\
\hline Age, y & $48.11 \pm 12.56$ & $37 \pm 13.73$ & 0.015 & $51 \pm 12.16$ & $36.62 \pm 12.63$ & - \\
\hline Height, cm & $174.33 \pm 7.09$ & $172.47 \pm 5.84$ & 0.237 & $171.23 \pm 5.25$ & $172.54 \pm 6.01$ & 0.376 \\
\hline Weight, kg & $83.36 \pm 13.5$ & $70.16 \pm 9.15$ & 0.001 & $76.64 \pm 5.9$ & $75.08 \pm 5.51$ & 0.352 \\
\hline $\mathrm{BMI}, \mathrm{kg} \cdot \mathrm{m}^{-2}$ & $27.35 \pm 3.5$ & $23.63 \pm 3.22$ & 0.002 & $26.16 \pm 1.93$ & $25.25 \pm 1.84$ & 0.784 \\
\hline
\end{tabular}

Data are presented as mean \pm SD. OSA obstructive sleep apnea, $B M I$ body mass index; ${ }^{*} P$-value after adjustment for age 


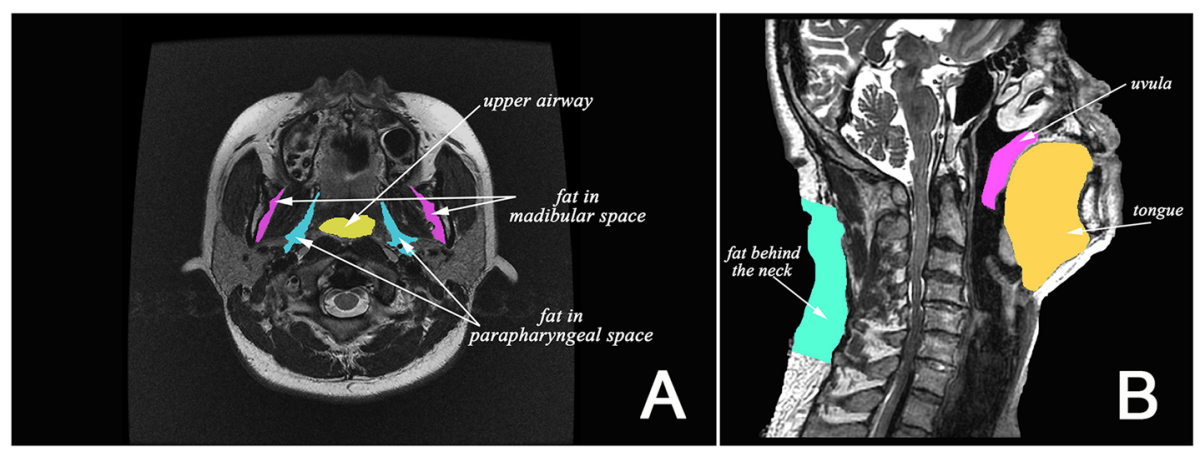

Fig. 1 Segmentation of partial tissues

Figure 2 defines some structural geometrical parameters on the midsagittal plane. The two lines defining the ends of UA in Fig. 2a represent the hard palate plane and the hyoid bone plane in the three-dimensional structure of the head and neck, respectively. A key parameter $\mathrm{h}$ proposed in this study, which is the distance from the upper edge of the second cervical vertebra to the hard palate plane, has never been investigated before. $\mathrm{L}_{\mathrm{HV}}$ is the distance between the top of the second cervical vertebra and the hyoid bone plane. $\mathrm{T}_{\mathrm{ST}}$ is the average thickness of the posterior cervical soft tissue. Figure $2 \mathrm{~b}$ shows the long axis $\left(\mathrm{L}_{\mathrm{LAX}}\right)$ and short axis $\left(\mathrm{L}_{\mathrm{SAX}}\right)$ of the tongue, and also the average thickness of the posterior cervical fat $\left(\mathrm{T}_{\mathrm{NF}}\right)$. The angles $\beta$ and $\theta$, which have also never been studied previously, together with the angle $\alpha$ are defined in Fig. 2c. The angle $\theta=\beta+\alpha-180^{\circ}$ can describe the level of head tilt. In addition, we also measure the neck circumference $\left(C_{N}\right)$ and a non-head and neck parameter, the waist circumference $\left(C_{W}\right)$, using a measuring tape.

\section{Quantitative evaluations of weight effects on upper airway length}

UA length $L_{U A}$ is the sum of $h$ and $L_{H V}$. Head tilt can affect not only $h$ but also $\mathrm{L}_{\mathrm{HV}}$. We express $\mathrm{L}_{\mathrm{UA}}$ and $\mathrm{L}_{\mathrm{HV}}$ as a linear function of the level of head tilt, or the angle $\theta: L_{U A}=a_{1} \theta+b_{1}$ and $L_{H V}=a_{2} \theta+b_{2}$. From the two equations, a $\Delta \theta$ increase in angle will increase the UA length by $\Delta \mathrm{L}_{\mathrm{UA}}=\mathrm{a}_{1} \Delta \theta$ and simultaneously result in an upward movement of the hyoid bone plane by an amount $\left|\Delta \mathrm{L}_{\mathrm{HV}}\right|=\left|\mathrm{a}_{2}\right| \Delta \theta$ in these healthy subjects. The hyoid position in OSA patients should be lower than in healthy subjects when there was no difference in the head tilt angle between the two groups. If the amount of downward movement of the hyoid, denoted by $\Delta \mathrm{L}_{\text {hyoid, }}$, in OSA patients is

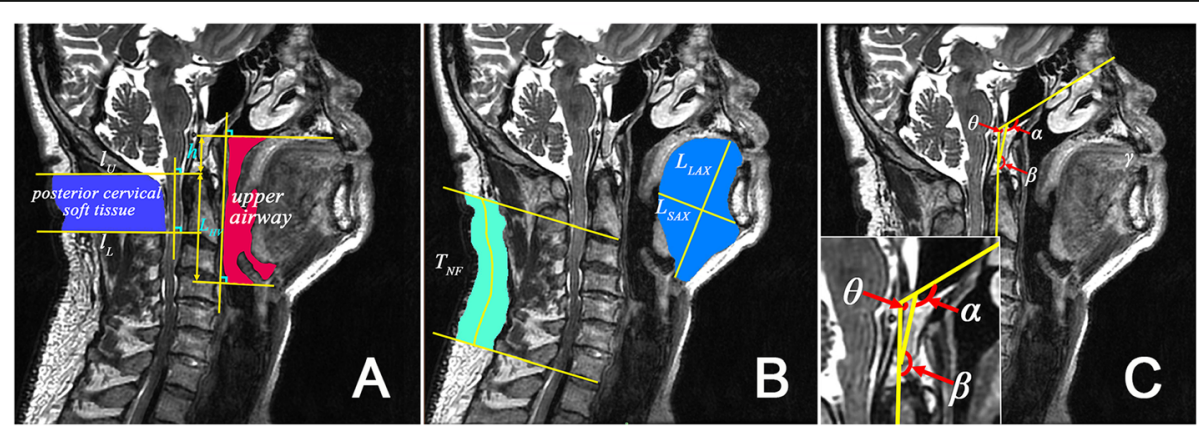

Fig. 2 Definitions of main parameters on the midsagittal plane. In a, the two lines drawn from the hard palate, near the top of the oral cavity, and the hyoid, which are also normal to the posterior wall, define the two ends of the upper airway. The parameter h, a part of the upper airway length, is the distance from the upper edge of the second cervical vertebra to the hard palate plane. The average thickness of the posterior cervical soft tissue $T_{S T}$ is calculated from the area surrounded by the three lines and skin dividing the distance between the two parallel lines passing through the upper and lower edges of the second cervical vertebra. In $\mathbf{b}$, the long axis of the tongue $L_{\text {LAX }}$ starts from the central point of the hyoid bone and ends at a point farthest from the hyoid on the tongue surface, and the short axis $L_{S A X}$ is the perpendicular bisector of $L_{L A X}$ ending on the tongue surfaces. The average thickness of the posterior cervical fat $T_{\mathrm{NF}}$ is calculated by the area of the fat beneath the skin, from the bottoms of the second to the sixth cervical vertebrae, dividing the length of the central line. In $\mathbf{c}$, The angles a and $\beta$ represent the relative positions among the occipital bone, cervical vertebra, and nasion: $\beta$ is the angle between the posterior wall of the upper airway and the occipital bone line drawn from the sellar to the tip of the clivus, and $a$ is the angle between the occipital bone line and the line drawn from the nasion to the sellar. $\theta$ is the angle between the posterior wall of the upper airway and the line drawn from the nasion to the sellar. The lower left corner is a magnification of the local region defining these three angles 
similar to the amount of upward movement $\left|\Delta \mathrm{L}_{\mathrm{HV}}\right|$ caused by an angle change $\Delta \theta^{\prime \prime}$ in healthy subjects, we can estimate the hyoid moving down caused by the large weight in OSA patients using $\Delta \mathrm{L}_{\text {hyoid }}=\left|\Delta \mathrm{L}_{\mathrm{HV}}\right|$ when $\Delta \theta^{\prime} \Delta \theta^{\prime \prime}$ or the expression $\Delta \mathrm{L}_{\text {hyoid }}=\left|\mathrm{a}_{2}\right| \Delta \theta^{\prime \prime}$. Therefore, the total increase in UA length resulted from head tilt and hyoid movement for patients is $\Delta \mathrm{L}_{\mathrm{OSA}}=\Delta \mathrm{L}_{\mathrm{UA}}+\Delta \mathrm{L}_{\text {hyoid }}=\mathrm{a}_{1} \Delta \theta+\left|\mathrm{a}_{2}\right| \Delta \theta^{\prime \prime}$. The contribution of the increase caused by $\Delta \theta$ to the total increase in UA length in patients is $\Delta \mathrm{L}_{\mathrm{UA}} / \Delta \mathrm{L}_{\mathrm{OSA}}=\Delta \theta$ / $\left(\Delta \theta+\left|\mathrm{a}_{2} / \mathrm{a}_{1}\right| \Delta \theta^{\prime \prime}\right)$, and the contribution of the downward movement of the hyoid is $\Delta \mathrm{L}_{\text {hyoid }} / \Delta \mathrm{L}_{\mathrm{OSA}}=\left|\mathrm{a}_{2}\right|$ $\mathrm{a}_{1} \mid \Delta \theta^{\prime \prime \prime} /\left(\Delta \theta+\left|\mathrm{a}_{2} / \mathrm{a}_{1}\right| \Delta \theta^{\prime \prime \prime}\right)$. Measuring $\mathrm{L}_{\mathrm{UA}}$ and $\mathrm{L}_{\mathrm{HV}}$ at different angles $\theta$ caused by different levels of head tilt in healthy subjects, we can determine the parameters $\mathrm{a}_{1}$ and $\mathrm{a}_{2}$ by fitting the data to the equations $\mathrm{L}_{\mathrm{UA}}=\mathrm{a}_{1} \theta+\mathrm{b}_{1}$ and $\mathrm{L}_{\mathrm{HV}}=\mathrm{a}_{2} \theta+\mathrm{b}_{2}$. The parameter $\Delta \theta^{*}$ can be determined by comparing the position of the hyoid bone plane between the OSA patients and healthy subjects, which will be addressed in detail in the Results section.

\section{Statistical analysis}

All morphological data measured from structures of OSA patients and healthy subjects were analyzed using the software SPSS (SPSS Inc., Chicago, USA). Independent-sample $t$ test was used in data comparisons between the patients and controls. Covariance analysis was used to adjust for age in the comparison between the patient and control groups with BMI matching. The value $p<0.05$ was considered as statistically significant. Correlation analysis was used to test relationships between measured parameters.

\section{Results}

\section{Statistical analysis of morphological parameters}

Table 2 lists the measured results of the histomorphological parameters. Comparing OSA patients to healthy subjects, there are significant differences in $h, \beta$, and $\mathrm{T}_{\mathrm{ST}}$. As shown in Fig. 3, the upper edge of the second cervical vertebra in OSA patients is generally under the hard palate plane $(h>0)$ while it is generally above the hard palate plane $(h<0)$ or near the hard palate plane in

Table 2 Histomorphological measurement results in male OSA patients and healthy subjects

\begin{tabular}{|c|c|c|c|c|c|c|}
\hline & \multicolumn{3}{|c|}{ No BMI matching } & \multicolumn{3}{|l|}{ BMI matching } \\
\hline & $\begin{array}{l}\text { OSA patients } \\
(n=18)\end{array}$ & $\begin{array}{l}\text { Healthy subjects } \\
(n=20)\end{array}$ & $P$ value & $\begin{array}{l}\text { OSA Patients } \\
(n=14)\end{array}$ & $\begin{array}{l}\text { Healthy subjects } \\
(n=13)\end{array}$ & $P$ value ${ }^{*}$ \\
\hline Length of the upper airway $\left(L_{\cup A}\right), m m$ & $82.79 \pm 6.02$ & $68.8 \pm 6.83$ & $<0.001$ & $81.99 \pm 5.88$ & $70.19 \pm 6.41$ & 0.001 \\
\hline Upper airway volume, $\mathrm{cm}^{3}$ & $12.71 \pm 5.25$ & $10.67 \pm 6.3$ & 0.285 & $11.67 \pm 3.91$ & $11.71 \pm 7.2$ & 0.66 \\
\hline $\begin{array}{l}\text { Narrowest cross-sectional area of the upper } \\
\text { airway }\left(\mathrm{S}_{\mathrm{NUA}}\right), \mathrm{mm}^{2}\end{array}$ & $25.1 \pm 19.41$ & $65.32 \pm 41.32$ & 0.001 & $22 \pm 15.86$ & $64.25 \pm 36.55$ & 0.001 \\
\hline $\begin{array}{l}\text { Average cross-sectional area of the upper } \\
\text { airway }\left(S_{A \cup A}\right), \mathrm{mm}^{2}\end{array}$ & $147.01 \pm 58.77$ & $167.12 \pm 74.89$ & 0.361 & $135.73 \pm 45.61$ & $177.82 \pm 83.27$ & 0.099 \\
\hline Fat volume in parapharyngeal space $\left(V_{P F}\right), \mathrm{cm}^{3}$ & $11.15 \pm 4.2$ & $6.25 \pm 2.73$ & $<0.001$ & $10.25 \pm 3.12$ & $7.17 \pm 2.87$ & 0.045 \\
\hline Fat volume in mandibular space $\left(\mathrm{V}_{\mathrm{MF}}\right), \mathrm{cm}^{3}$ & $3.65 \pm 1.72$ & $1.73 \pm 0.75$ & $<0.001$ & $3.71 \pm 1.51$ & $1.58 \pm 0.74$ & 0.002 \\
\hline Thickness of posterior cervical fat $\left(T_{\mathrm{NF}}\right), \mathrm{mm}$ & $17 \pm 5.43$ & $13.22 \pm 5.8$ & 0.037 & $15.67 \pm 4$ & $15.18 \pm 4.84$ & 0.623 \\
\hline $\begin{array}{l}\text { Fat area in parapharyngeal space in the neck } \\
\text { plane with the narrowest upper airway }\left(S_{N P F}\right), m^{2}\end{array}$ & $279.37 \pm 130.91$ & $176.2 \pm 116.17$ & 0.015 & $262.07 \pm 139.68$ & $197.96 \pm 116.38$ & 0.072 \\
\hline Thickness of soft tissue behind neck $\left(T_{\mathrm{ST}}\right), \mathrm{mm}$ & $63.97 \pm 7.39$ & $50.03 \pm 6.84$ & $<0.001$ & $62.29 \pm 5.26$ & $52.65 \pm 5.05$ & $<0.001$ \\
\hline Tongue volume $\left(\mathrm{V}_{\mathrm{TG}}\right), \mathrm{cm}^{3}$ & $138.23 \pm 13.79$ & $119.21 \pm 12.64$ & $<0.001$ & $136.41 \pm 10.4$ & $122.01 \pm 13.15$ & $<0.001$ \\
\hline Length of the long axis of tongue $\left(L_{L A X}\right), m m$ & $82.65 \pm 7.76$ & $68.33 \pm 5.81$ & $<0.001$ & $81.31 \pm 6.87$ & $69.94 \pm 6.13$ & 0.002 \\
\hline Length of the short axis of tongue $\left(\mathrm{L}_{\mathrm{SAX}}\right), \mathrm{mm}$ & $48.13 \pm 4.48$ & $50.73 \pm 6.17$ & 0.151 & $48.25 \pm 4.38$ & $51.38 \pm 5.18$ & 0.588 \\
\hline Ratio of the long to short axis of tongue, & $1.73 \pm 0.21$ & $1.37 \pm 0.26$ & $<0.001$ & $1.7 \pm 0.23$ & $1.38 \pm 0.24$ & 0.027 \\
\hline $\begin{array}{l}\text { Distance from the top of the second cervical } \\
\text { vertebra to hyoid bone plane }\left(L_{H V}\right), m m\end{array}$ & $70.09 \pm 6.4$ & $69.37 \pm 8.2$ & 0.764 & $71.45 \pm 6.37$ & $67.96 \pm 8.23$ & 0.822 \\
\hline $\begin{array}{l}\text { Distance from the top of the second cervical } \\
\text { vertebra to hard palate plane (h), } \mathrm{mm}\end{array}$ & $12.42 \pm 7.71$ & $-0.76 \pm 6.06$ & $<0.001$ & $10.31 \pm 5.9$ & $1.11 \pm 5.22$ & 0.001 \\
\hline$a^{\circ}$ & $140.04 \pm 6.08$ & $144.67 \pm 6.08$ & 0.027 & $139.73 \pm 6.8$ & $145.24 \pm 6.24$ & 0.029 \\
\hline$\beta,^{\circ}$ & $149.05 \pm 8.54$ & $134.55 \pm 6.27$ & $<0.001$ & $147.11 \pm 7.11$ & $135.85 \pm 5.55$ & $<0.001$ \\
\hline$\theta$, & $109.04 \pm 10.67$ & $99.22 \pm 4.82$ & 0.002 & $106.62 \pm 9.99$ & $101.09 \pm 4.52$ & 0.23 \\
\hline Neck circumference, $\left(C_{N}\right), c m$ & $40.76 \pm 2.14$ & $36.56 \pm 1.91$ & $<0.001$ & $40.25 \pm 1.44$ & $36.87 \pm 2.20$ & $<0.001$ \\
\hline Waist circumference, $\left(C_{W}\right), c m$ & $97.36 \pm 9.19$ & $86.08 \pm 8.77$ & 0.001 & $94.06 \pm 5.49$ & $89.92 \pm 7.34$ & 0.133 \\
\hline
\end{tabular}

Data are presented as mean \pm SD. OSA obstructive sleep apnea, $B M I$ body mass index; *: $P$-value after adjustment for age 


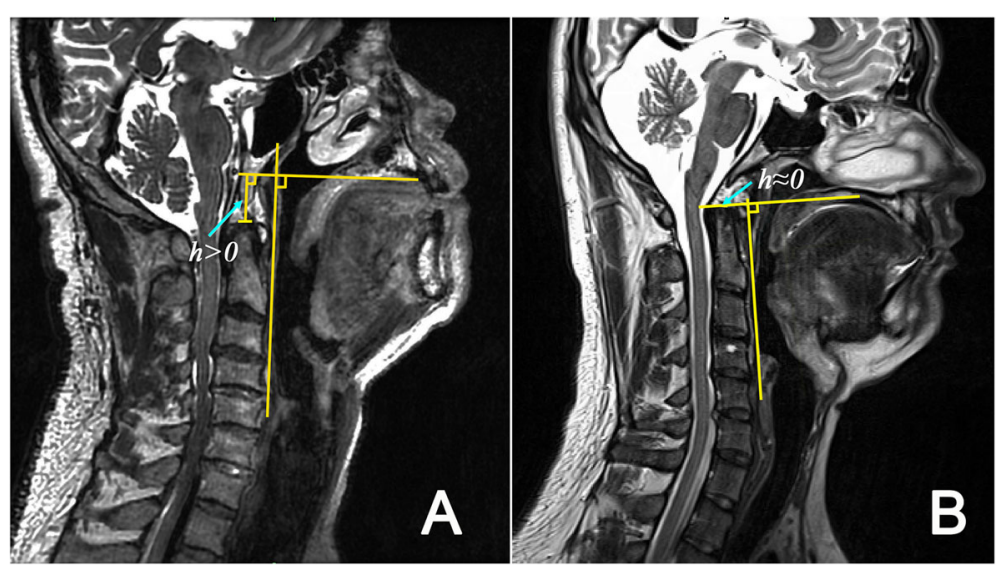

Fig. 3 The relative position between the upper edge of the second cervical vertebra and the hard palate plane, a for obstructive sleep apnea patients and $\mathbf{b}$ for healthy subjects

healthy subjects. There is a significant difference in $\mathrm{h}$ between healthy subjects and OSA patients whether BMI is matched or not (both $p<0.001$ ). The mean value of $\beta$ for OSA patients is much larger than in healthy groups with and without BMI matching (both $p<0.001$ ). The mean value of $\alpha$ of OSA patients is smaller than in healthy subjects with BMI matching $(p=0.042)$ or without $(p=$ 0.027 ), which is consistent with the statistical results of Neelapu et al. [25] A correlation analysis for all 38 subjects in healthy and patient groups shows a negative correlation between the angles $\alpha$ and $\beta(r=0.465, p=0.004)$.

As shown in Table 2, OSA patients have longer UA than healthy subjects whether BMI is matched or not (both $p<0.001$ ). UA length $\mathrm{L}_{\mathrm{UA}}$ has strong correlation with BMI $(r=0.573, p<0.001), \mathrm{C}_{\mathrm{N}}(r=0.674, p<0.001)$, and $\mathrm{C}_{\mathrm{w}}(r=0.861, p<0.001)$ respectively, suggesting that body weight $(\mathrm{W})$ plays an important role in $\mathrm{L}_{\mathrm{UA}}$ change. Figure 4 shows that $\mathrm{W}, \mathrm{L}_{\mathrm{LAX}}, \mathrm{T}_{\mathrm{ST}}, \theta, \beta$, and $\mathrm{h}$ are all strongly correlated with $\mathrm{L}_{\mathrm{UA}}(p<0.001)$. $\mathrm{L}_{\mathrm{UA}}$ also shows a weak negative correlation with $\alpha(r=-0.324, p=$ $0.051)$. Figure 5 shows that $\mathrm{h}(p<0.001), \mathrm{T}_{\mathrm{ST}}(p<0.001)$, $\beta(p=0.003)$, and $\mathrm{L}_{\mathrm{LAX}}(p<0.001)$ are strongly correlated with W. One can see from Table 2, Fig. 4a, and Fig. 5 that although the body weight in BMI matching patient and control groups is similar $(p=0.765)$, there are still significant differences in $\mathrm{L}_{\mathrm{UA}}, \mathrm{h}, \mathrm{T}_{\mathrm{ST}}, \beta, \mathrm{L}_{\mathrm{LAX}}$ and $\mathrm{C}_{\mathrm{N}}$ between the two groups (all $p<0.001$ ), but $\alpha$ is unrelated to $\mathrm{W}(r=-0.107, p=0.528)$.

Interestingly, the slopes of the two dashed lines for OSA patients and healthy subjects in Figs. $4 \mathrm{a}$ and 5 are almost the same, suggesting that the variation of these parameters with body weight are the same in the two groups. However, there is a distance between the two lines, showing differences in these morphological parameters. We can infer that the weight effect on morphological parameters such as UA length is not only from the increased total body weight, but also from the distribution of weight gained.

Larger weight can lead to longer UA in both healthy subjects and OSA patients. However, from the BMI matching data in Table 2, we can see that the parameters $\mathrm{C}_{\mathrm{N}}$ and $\mathrm{T}_{\mathrm{ST}}$ in the patient group are significantly larger than in the healthy group, which leads to larger $\theta$ and $\beta$. In order to evaluate the contributions of the head tilt angle on UA morphology, we use MRI results obtained from 19 healthy subjects with partial and a maximum chin elevations. The results indicate that, with the increase in the head tilt angle, the position of the hard palate and the hyoid moved upward relative to the cervical vertebra, resulting in an increase in $\mathrm{h}$ and a decrease in $\mathrm{L}_{\mathrm{HV}}$. By fitting the data at different head tilt angles, we obtain $\mathrm{a}_{1}=$ 0.457 and $\mathrm{a}_{2}=-0.946$ in the equations given in the Methods section, and then we obtain $\left|\mathrm{a}_{2} / \mathrm{a}_{1}\right|=2.07$.

The data without BMI matching in Table 2 shows that $\theta$ in the OSA patient group was $10^{\circ}$ larger than in the healthy group, while the distance $\mathrm{L}_{\mathrm{HV}}$ was almost the same. This indicates that the hyoid position in OSA patients should be lower than in healthy subjects when there was no difference in the head tilt angle between the two groups, and the amount of downward movement of the hyoid in OSA patients should be similar to the amount of upward movement caused by the $10^{\circ}$ change in $\theta$ in healthy subjects. Thus, the parameter $\Delta \theta^{*}=10^{\circ}$, and the large weight leads to the hyoid moving down by $\Delta \mathrm{L}_{\text {hyoid }}=10\left|\mathrm{a}_{2}\right|$ in OSA patients. Therefore, in addition to the effect of increased head tilt angle while gaining weight, the downward movement of the hyoid bone is another major reason of UA lengthening in patients. The contribution of $\Delta \theta$ is $\Delta \mathrm{L}_{\mathrm{UA}} / \Delta \mathrm{L}_{\mathrm{OSA}}=\Delta \theta /$ $(\Delta \theta+20.7)$, and the contribution of the downward movement of the hyoid is $\Delta \mathrm{L}_{\text {hyoid }} / \Delta \mathrm{L}_{\mathrm{OSA}}=20.7 /(\Delta \theta+$ 20.7). Therefore, we can estimate that when the head tilt 
A

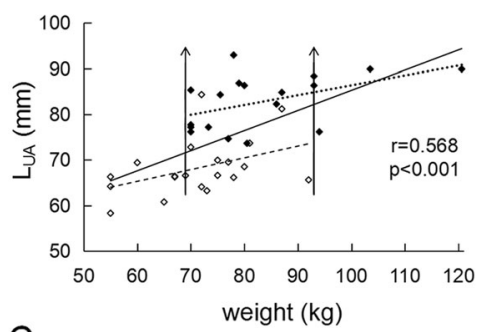

C

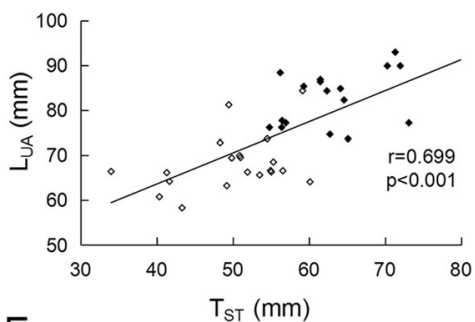

$\mathrm{E}$

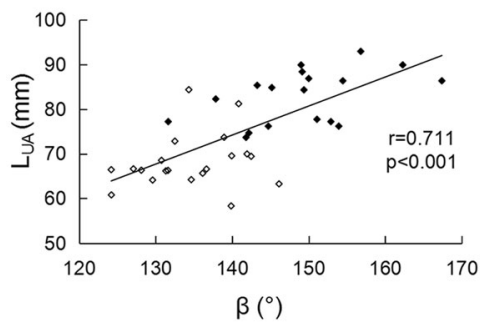

B
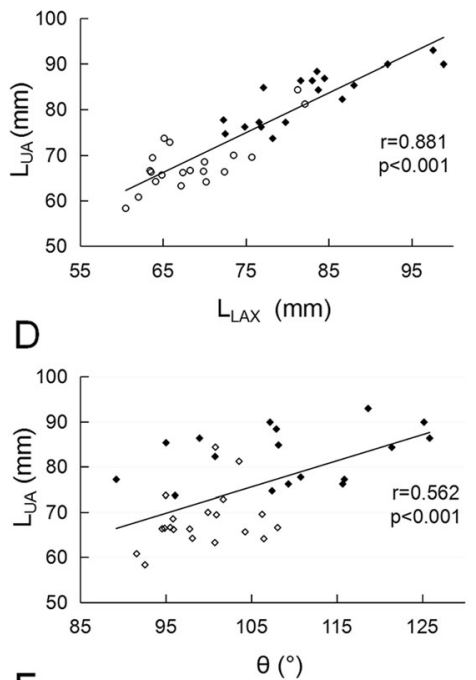

$\mathrm{F}$

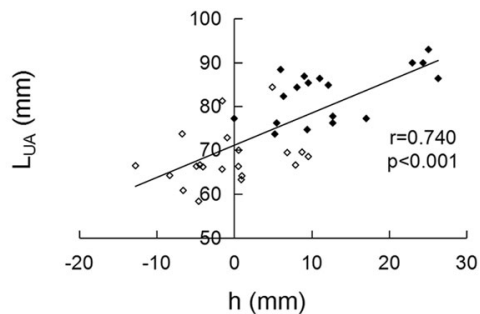

Fig. 4 Correlations of the upper airway length $L_{U A}$ with $\mathbf{a}$ the body weight $W, \mathbf{b}$ the length of the long axis of tongue $L_{L A X}, \mathbf{c}$ the thickness of soft tissue behind the neck $T_{S T}, \mathbf{d}$ the angle $\theta$, e the angle $\beta$, and $\mathbf{f}$ the distance from the top of second cervical vertebra to hard palate plane $h$ in all subjects. Solid symbols represent obstructive sleep apnea patients and hollow symbols are healthy subjects. Solid lines are the fitting results for data from all subjects. The upper and lower dashed lines in subfigure a are fitting results for patients and healthy subjects, respectively. The two vertical lines indicate the weight range with body mass index matching in patient and healthy groups

angle in OSA patients is $5-10^{\circ}$ larger than in healthy people, head tilt contributes about $19.5-32.6 \%$ or roughly $1 / 5-1 / 3$, and the hyoid moving down contributes $67.4-80.5 \%$ or roughly $2 / 3-4 / 5$, to the increase in UA length in OSA patients.

The data for BMI matching in Table 2 indicates that the tongue volume $\mathrm{V}_{\mathrm{TG}}$ of OSA patients is significantly larger than in healthy subjects $(p=0.007)$. This suggests that although the two groups have similar body weight, there is more fat in the tongue, and therefore a larger tongue, for patients. Due to the limited space in the anterior-posterior direction, there is no significant difference in $\mathrm{L}_{\mathrm{SAX}}$ between patients and healthy people $(p=0.114)$. Therefore, an enlarged tongue will lead directly to an increase in $\mathrm{L}_{\mathrm{LAX}}(p<$ 0.001 ) and a downward movement of the hyoid bone. This is consistent with the observations of Chi et al. [16] Although there are significant differences in the narrowest cross-sectional area of UA $\left(\mathrm{S}_{\mathrm{NUA}}\right)$ between OSA patients and healthy subjects $(p=0.001)$, there are no significant differences in the average cross- sectional area of UA $\left(\mathrm{S}_{\mathrm{AUA}}\right)(p=0.361)$ and UA volume $(p=0.285)$. This is due to stronger genioglossus reactions in patients under waking condition [26-28], which can keep the size of UA cross-section steady to maintain normal breathing.

Compared with healthy subjects, OSA patients have larger neck circumference $\mathrm{C}_{\mathrm{N}}$, BMI matched or not, and obvious fat depositions in some neck regions. In the OSA patients, the volume of fat in the parapharyngeal space $V_{P F}$ and mandibular space $V_{M F}$ both increase significantly compared to healthy subjects, BMI matched or not. The thickness of posterior cervical fat $\mathrm{T}_{\mathrm{NF}}$ and waist circumference $C_{W}$ increase with weight increase. The data for BMI matching showed that for similar body weight, there is no significant difference in $T_{N F}$ or $C_{W}$ between patients and healthy subjects.

\section{Correlation analysis between morphological parameters and $\mathrm{AHI}$}

The correlation analysis for the data of 18 OSA patients shows that AHI is strongly correlated with UA length 

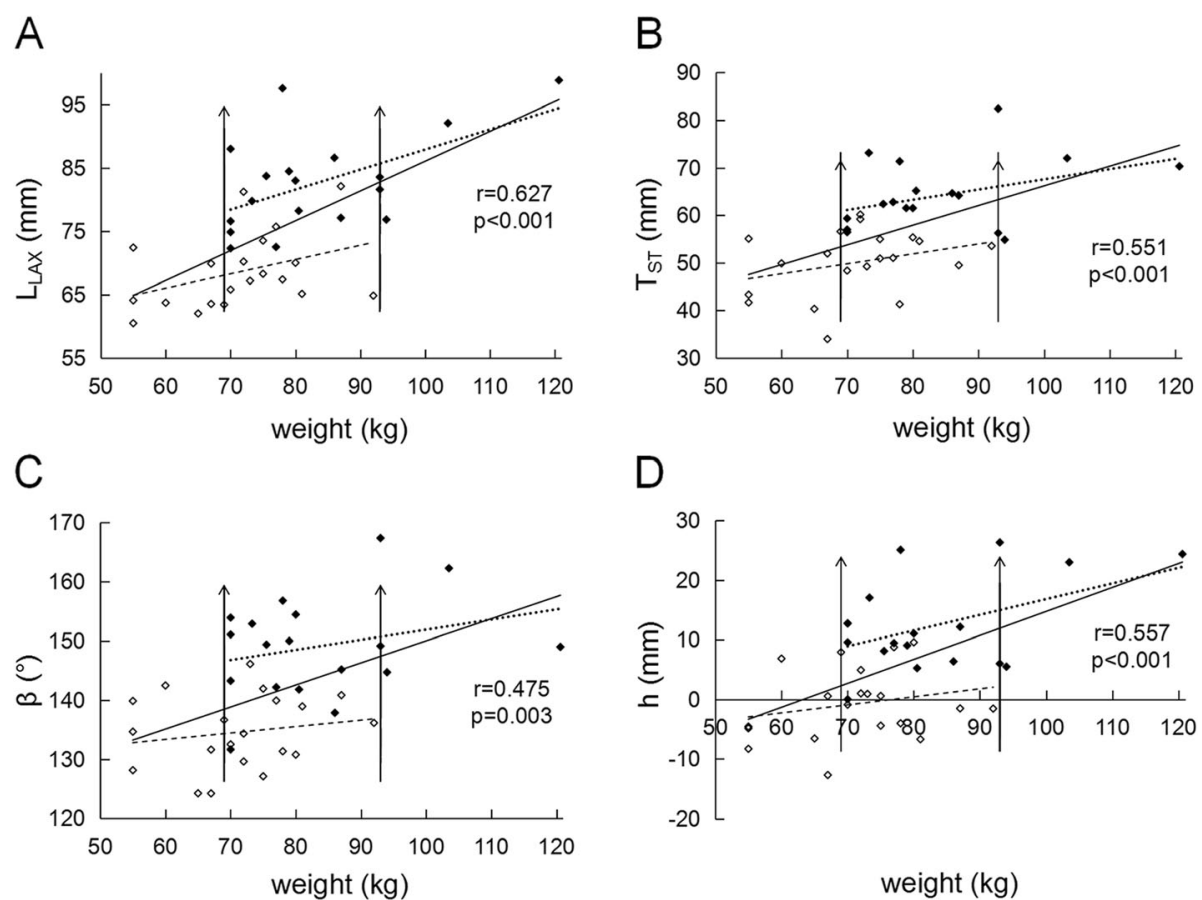

weight $(\mathrm{kg})$

Fig. $\mathbf{5}$ Correlations of the body weight $W$ with $\mathbf{a}$ the length of the long axis of tongue $L_{L A X}, \mathbf{b}$ the thickness of soft tissue behind the neck $T_{S T}$, $\mathbf{c}$ the angle $\beta$, and $\mathbf{d}$ the distance from the top of second cervical vertebra to hard palate plane $\mathrm{h}$ in all subjects. Solid symbols represent obstructive sleep apnea patients and hollow symbols are healthy subjects. Solid lines are the fitting results for data from all subjects. The upper and lower dashed lines are the fitting results for patients and healthy subjects, respectively. The two vertical lines indicate the weight range with body mass index matching in patient and healthy groups

(Fig. 6a), h (Fig. 6b), $\beta$ (Fig. 6c), the fat area in parapharyngeal space in the neck plane with the narrowest UA $\left(\mathrm{S}_{\mathrm{NPF}}\right) \quad(r=0.478, p=0.045)$, and waist circumference $(r=0.625, p=0.013)$. Although $\mathrm{S}_{\mathrm{NUA}}$ and $\mathrm{C}_{\mathrm{N}}$ are significantly different between patients and healthy subjects, there is no significant correlation between AHI and $\mathrm{S}_{\mathrm{NUA}}$ or $\mathrm{C}_{\mathrm{N}}$. There is no significant correlation between AHI and $V_{\mathrm{PF}}, \mathrm{V}_{\mathrm{MF}}, \mathrm{T}_{\mathrm{NF}}$ in OSA patients, but $\mathrm{AHI}$ shows strong positive correlations with $\mathrm{V}_{\mathrm{TG}}(r=0.569, p=$ 0.017), and $\mathrm{L}_{\mathrm{LAX}}$ (Fig. 6d).

\section{Discussion}

This is the first study to address quantitatively the effect of body weight on UA length, and therefore UA collapsibility. By systematic morphological measurements on tissues surrounding UA and quantitative analyses, the study reveals the roles played by body weight in UA lengthening and obstruction. In addition to confirming that UA of OSA patients is much longer than in healthy subjects, and that $\mathrm{L}_{\mathrm{UA}}$ is positively correlated with $\mathrm{AHI}$ as observed in some studies [8], we find the significant impact of body weight on $\mathrm{L}_{\mathrm{UA}}$ and the mechanism of UA lengthening in obese people, suggesting that weight gain increases $\mathrm{L}_{\mathrm{UA}}$ and the risk of UA collapse during sleep. In a study involving 24 weeks of weight loss, the investigators observed a decrease in the distance between the hard palate and hyoid bone in OSA patients [21]. This reflects our own observations, which show that weight change will lead to $\mathrm{L}_{\mathrm{UA}}$ change in the same direction.

It sounds amazing that weight increase can make UA longer. A clarification of its mechanism is particularly important for the treatment of OSA. From our hypothesis and findings, there are two points that merit special attention. One is the impact of the total weight increase, and the other is the impact of the regional distribution of the increased weight. Our results show that the distance $h$ increases with weight increase in both OSA patients and healthy people, but the increment is different after weight matching. We can explain this as follows: Table 2 shows that $\mathrm{T}_{\mathrm{ST}}$ in OSA patients is significantly larger than in healthy subjects, BMI matched or not. This increase in thickness will tilt the head farther back, increasing $\beta$, which then leads to an increase in the distance $h$ and therefore lengthens UA. Another reason for airway lengthening is that the pulling and squeezing on the surrounding tissues of the airway due to fat deposition, especially the expansion of tongue volume, will push the hyoid down and increase $\mathrm{L}_{\mathrm{HV}}$. Obesity leads to the increase of fat content in the genioglossal muscle [20], which can increase tongue size. Our results show that the tongue volume $\mathrm{V}_{\mathrm{TG}}$ in OSA patients is significantly larger than in healthy subjects. The head tilt angle 

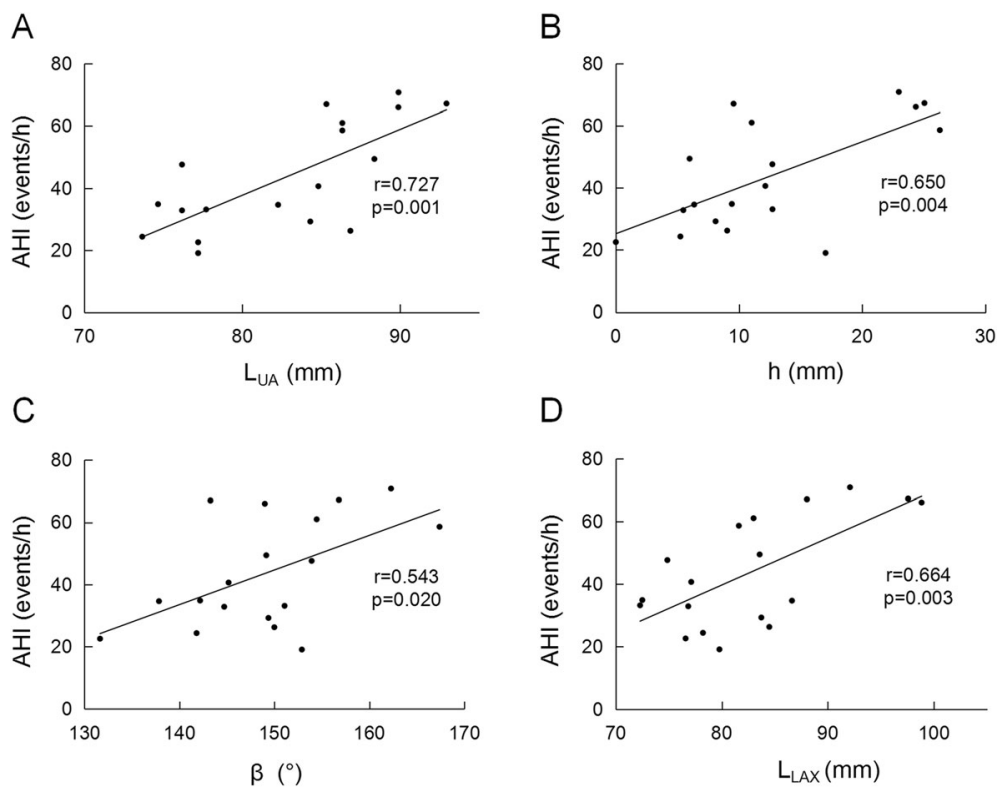

Fig. 6 The correlations between apnea-hypopnea index $(A H I)$ and $\mathbf{a}$ upper airway length $L_{\cup A}, \mathbf{b}$ distance from hard palate plane to the top of second cervical spine $h, \mathbf{c}$ angle $\beta$, and $\mathbf{d}$ length of the long axial of the tongue $L_{L A X}$ in obstructive sleep apnea patients

and hyoid downward displacement are both related to the fat increase. This can explain morphologically why not all obese people suffer from OSA. We found that OSA patients have a $5-10^{\circ}$ larger head tilt angle than in healthy people due to their large $\mathrm{T}_{\mathrm{ST}}$, and the contributions of hyoid downward movement and head tilt on the change in $\mathrm{L}_{\mathrm{UA}}$ are $67.4-80.5 \%$ and $19.5-32.6 \%$, respectively. Although the amount of weight and the distribution of deposited fat will both affect $\mathrm{L}_{\mathrm{UA}}$, Fig. 4a shows that the impact of fat distribution is larger than the increased amount of weight, which proves our hypothesis.

We grouped subjects not only with matched BMI between OSA patients and healthy subjects, but also without BMI matching to extend the weight range. From the BMI matching groups, we can observe the difference of fat distribution in the head and neck between the patient and healthy groups and analyze its impacts on respiratory functions. From the groups without BMI matching, we can observe some important phenomena over a large weight range, such as the changes in the parameters $h$, $\beta, V_{\mathrm{TG}}, \mathrm{L}_{\mathrm{LAX}}$ and $\mathrm{L}_{\mathrm{UA}}$ with weight. Our study shows that fat distribution plays a key role in evaluating the changes in UA length. Because BMI is an overall parameter that cannot provide any distribution information, it is therefore hard to effectively evaluate the impact of weight increase on the occurrence of OSA for an individual patient using BMI only.

The fat in the head and neck accumulates when weight increases in OSA patients. Some previous studies have found that parapharyngeal fat pads can narrow UA [29], while other data do not show such effects [30]. Our results show significant differences in $\mathrm{V}_{\mathrm{PF}}$ and $\mathrm{V}_{\mathrm{MF}}$ between OSA patients and healthy subjects, and $\mathrm{S}_{\mathrm{NPF}}$ correlates with AHI. This suggests that fat accumulated at the parapharyngeal and mandibular areas will directly compress UA. Therefore, obesity has a double effect on the morphology of UA in OSA patients. On the one hand, it will lengthen UA. On the other hand, the increase of fat around the pharynx will squeeze and narrow UA when most of the dilator muscle activations are lost during sleep. Both factors make airway collapse and obstruction more likely during sleep in OSA patients. Our results show that the parameter $\mathrm{S}_{\mathrm{NUA}}$ in OSA patients is significantly smaller than in healthy subjects, but there is no correlation between $\mathrm{S}_{\mathrm{NUA}}$ and AHI. This is not surprising because the images were taken while awake rather than sleeping, and therefore the parameter $\mathrm{S}_{\mathrm{NUA}}$ only reflects the narrowest caliber of UA while awake. Because dilator muscle activities can be very different among patients under waking condition for maintaining normal breathing, the distribution of the narrowed size of UA obtained under such a condition can be very different from that during sleep, when most of dilator muscle activities are lost.

We should mention that the number of patients included in the study is still small and all subjects in this study are male. The population of males with OSA is much higher than females [31], and we design, as the first step, the comparisons of morphological parameters between male healthy subjects and patients to study the effects of body weight on the airway length and therefore on OSA. Further investigations are needed to see 
whether the important conclusions of this study can be extend to females. Another limitation is that our patient group does not include mild OSA patients with AHI between 5 and 15 . We only measured and analyzed data for moderate and severe OSA patients with AHI $>15$ in this study. In addition, the subjects participated in this study are Chinese. We do not know whether the findings of this study can be applied to other population groups.

\section{Conclusions}

The important findings in this study prove our hypothesis, and reveal that although the amount of body weight and the distribution of deposited fat both affect airway length, and therefore OSA, the impact of fat distribution is larger than that of weight increase, and is a better predictor of who among obese people are more prone to OSA. The findings in this study can lead to a better understanding of OSA mechanism and will be of great significance in developing effective treatments for OSA.

\begin{abstract}
Abbreviations
AHI: The apnea-hypopnea index; BMI: The body mass index; $C_{N}$ : The neck circumference; $C_{w}$ : The waist circumference; $h$ : The distance from the upper edge of the second cervical vertebra to the hard palate plane; L L distance between the top of the second cervical vertebra to the hyoid bone plane; $L_{L A X}$ : The long axis of the tongue; $L_{S A X}$ : The short axis of the tongue; LUA: The upper airway length; MRI: Magnetic resonance imaging;

OSA: Obstructive sleep apnea; $\mathrm{S}_{\text {AUA }}$ : The average cross-sectional area of the upper airway; SNPF: $_{\text {The }}$ area of fat in parapharyngeal space in the neck plane with the narrowest upper airway; $S_{\text {NUA: }}$ : The narrowest cross-sectional area of the upper airway; $T_{N F}$ : The average thickness of the posterior cervical fat; $\mathrm{T}_{\mathrm{ST}}$ : The average thickness of the posterior cervical soft tissue; UA: The upper airway; $V_{M F}$ : The volume of fat in the mandibular space; $V_{P F}$ : The volume of fat in the parapharyngeal space; $\mathrm{V}_{\mathrm{TG}}$ : The tongue volume; $\mathrm{W}$ : The body weight; $\mathrm{a}$ : The angle between the occipital bone line and the line drawn from the nasion to the sellar; $\beta$ : The angle between the posterior wall of the upper airway and the occipital bone line drawn from the sellar to the tip of the clivus; $\theta$ : The angle between the posterior wall of the upper airway and the line drawn from the nasion to the sellar; $\Delta \mathrm{L}_{\text {hyoid: }}$ The downward moving distance of the hyoid bone; $\Delta \mathrm{L}_{\text {OSA }}$ : The total increase in the upper airway length resulted from head tilt and hyoid movement; $\Delta$ LUA $_{\text {A }}$ The increase in the upper airway length; $\Delta \theta$ : The increase in the angle $\theta$
\end{abstract}

\section{Acknowledgments}

We thank all patients and healthy subjects who participated in this study.

\section{Authors' contributions}

$Y H, H Y L, H X$, and $C J$ contributed to the conception and design of the study. $H Y L, C W, Y L, Y A, G L, J G, H Z, T L, Z L$, and JX contributed to the collection of data. $H Y L, H X, C J, X H, H L$, and $Y H$ contributed to the analysis and interpretation of data. HYL, CJ, HX, and YH contributed to the drafting of the manuscript. All authors read and approved the final manuscript.

\section{Funding}

This work is supported by grants from the National Natural Science Foundation of China (31670959 and 81171422), the National Science and Technology Pillar Program of China (2012BAI05B03), and the Key Projects in Science and Technology Program of Beijing Municipal Education Commission, China (KZ201210025022).

\section{Availability of data and materials}

The datasets used and/or analysed during the current study are available from the corresponding author on reasonable request.

\section{Ethics approval and consent to participate}

The research protocol was approved by the Ethics Committee of the Capital Medical University, Beijing, China (2013SY67). All subjects provided written informed consent prior to participation.

\section{Consent for publication}

Not applicable.

\section{Competing interests}

The authors declare that they have no competing interests.

\section{Author details}

${ }^{1}$ School of Biomedical Engineering, Capital Medical University, 10 Xitoutiao, Youanmenwai, Beijing 100069, China. ${ }^{2}$ Beijing Key Laboratory of Fundamental Research on Biomechanics in Clinical Application, Capital Medical University, Beijing, China. ${ }^{3}$ Department of Radiology, Beijing Tongren Hospital, Capital Medical University, No 1 Dongjiaominxiang Street, Beijing 100730, China.

Received: 4 March 2020 Accepted: 4 October 2020

Published online: 19 October 2020

\section{References}

1. Malhotra A, White DP. Obstructive sleep apnoea. Lancet. 2002;360:237-45.

2. Wu H, Wang M, Wang J, An Y, Wang H, Huang Y. Direct visualizations of air flow in the human upper airway using in-vitro models. Sci China Life Sci. 2019:62:235-43.

3. Wang $\mathrm{S}$, Zhang $\mathrm{H}$, Huang $\mathrm{X}$, et al. A pilot study in male patients to show the effects of natural fluid shift on the severity of obstructive sleep apnea. Sleep Breath. 2020. https://doi.org/10.1007/s11325-020-02044-x.

4. Malhotra A, Huang Y, Fogel RB, et al. The male predisposition to pharyngeal collapse: importance of airway length. Am J Respir Crit Care Med. 2002;166: 1388-95.

5. Finkelstein $Y$, Wolf $L$, Nachmani A, et al. Velopharyngeal anatomy in patients with obstructive sleep apnea versus normal subjects. J Oral Maxillofac Surg. 2014;72:1350-72.

6. Dentino K, Ganjawalla K, Inverso G, Mulliken JB, Padwa BL. Upper airway length is predictive of obstructive sleep apnea in syndromic craniosynostosis. J Oral Maxillofac Surg. 2015;73:S20-5.

7. Susarla SM, Abramson ZR, Dodson TB, Kaban LB. Cephalometric measurement of upper airway length correlates with the presence and severity of obstructive sleep apnea. J Oral Maxillofac Surg. 2010;68:2846-55.

8. Segal Y, Malhotra A, Pillar G. Upper airway length may be associated with the severity of obstructive sleep apnea syndrome. Sleep Breath. 2008;12: 311-6.

9. Sutherland K, Lee RW, Cistulli PA. Obesity and craniofacial structure as risk factors for obstructive sleep apnoea: impact of ethnicity. Respirology. 2012; 17:213-22.

10. Ito E, Tsuiki S, Maeda K, Okajima I, Inoue Y. Oropharyngeal crowding closely relates to aggravation of OSA. Chest. 2016;150:346-52.

11. Tuomilehto H, Seppä J, Uusitupa M. Obesity and obstructive sleep apneaclinical significance of weight loss. Sleep Med Rev. 2012;17:321-9.

12. Newman AB, Foster G, Givelber R, Nieto FJ, Redline S, Young T. Progression and regression of sleep-disordered breathing with changes in weight: the sleep heart health study. Arch Intern Med. 2005;165:2408-13.

13. Peppard PE, Young T, Palta M, Dempsey J, Skatrud J. Longitudinal study of moderate weight change and sleep-disordered breathing. JAMA. 2000;284: $3015-21$.

14. Young T, Peppard PE, Taheri S. Excess weight and sleep-disordered breathing. J Appl Physiol (1985). 2005;99:1592-9.

15. Schellenberg JB, Maislin G, Schwab RJ. Physical findings and the risk for obstructive sleep apnea, the importance of oropharyngeal structures. Am J Respir Crit Care Med. 2000;162:740-8

16. Chi L, Comyn FL, Mitra N, et al. Identification of craniofacial risk factors for obstructive sleep apnoea using three-dimensional MRI. Eur Respir J. 2011;38: 348-58

17. McGinley BM, Schwartz AR, Schneider H, Kirkness JP, Smith PL, Patil SP. Upper airway neuromuscular compensation during sleep is defective in obstructive sleep apnea. J Appl Physiol (1985). 2008;105:197-205. 
18. Pahkala R, Seppä J, Ikonen A, Smirnov G, Tuomilehto H. The impact of pharyngeal fat tissue on the pathogenesis of obstructive sleep apnea. Sleep Breath. 2014;18:275-82.

19. Li Y, Lin N, Ye J, Chang Q, Han D, Sperry A. Upper airway fat tissue distribution in subjects with obstructive sleep apnea and its effect on retropalatal mechanical loads. Respir Care. 2012:57:1098-105.

20. Kim AM, Keenan BT, Jackson N, et al. Tongue fat and its relationship to obstructive sleep apnea. Sleep. 2014;37:1639-48.

21. Sutherland K, Lee RW, Phillips CL, et al. Effect of weight loss on upper airway size and facial fat in men with obstructive sleep apnoea. Thorax. 2011;66:797-803.

22. An Y, Li Y, Liu Z, et al. Effects of fluid shift on upper airway patency and neck circumference in normal-weight subjects. Sleep Med. 2015;16(11): 1419-26.

23. Lin $\mathrm{H}$, Wang $\mathrm{C}$, Zhang $\mathrm{H}$, et al. Threshold of the upper airway cross-section for hypopnea onset during sleep and its identification under waking condition. Resp Res. 2019:20:280.

24. An Y, Ji C, Li Y, Wang J, Zhang X, Huang Y. In vivo measurements of human neck skin elasticity using MRI and finite element modeling. Med Phys. 2017; 44(4):1402-7.

25. Neelapu BC, Kharbanda OP, Sardana HK, et al. Craniofacial and upper airway morphology in adult obstructive sleep apnea patients: a systematic review and meta-analysis of cephalometric studies. Sleep Med Rev. 2017;31:79-90.

26. Mezzanotte WS, Tangel DJ, White DP. Waking genioglossal electromyogram in sleep apnea patients versus normal controls (a neuromuscular compensatory mechanism). J Clin Invest. 1992;89:1571-9.

27. Pierce $R$, White $D$, Malhotra A, et al. Upper airway collapsibility, dilator muscle activation and resistance in sleep apnoea. Eur Respir J. 2007;30:34553.

28. Carberry JC, Jordan AS, White DP, Wellman A, Eckert DJ. Upper airway collapsibility (Pcrit) and pharyngeal dilator muscle activity are sleep stage dependent. Sleep. 2016;39:511-21.

29. Shelton KE, Woodson H, Gay S, Suratt PM. Pharyngeal fat in obstructive sleep apnea. Am Rev Respir Dis. 1993;148:462-6.

30. Schwab RJ, Pasirstein M, Pierson R, et al. Identification of upper airway anatomic risk factors for obstructive sleep apnea with volumetric magnetic resonance imaging. Am J Respir Crit Care Med. 2003:168:522-30.

31. Peppard PE, Young T, Barnet JH, Palta M, Hagen EW, Hla KM. Increased prevalence of sleep-disordered breathing in adults. Am J Epidemiol. 2013; 177:1006-14.

\section{Publisher's Note}

Springer Nature remains neutral with regard to jurisdictional claims in published maps and institutional affiliations.

Ready to submit your research? Choose BMC and benefit from:

- fast, convenient online submission

- thorough peer review by experienced researchers in your field

- rapid publication on acceptance

- support for research data, including large and complex data types

- gold Open Access which fosters wider collaboration and increased citations

- maximum visibility for your research: over $100 \mathrm{M}$ website views per year

At $\mathrm{BMC}$, research is always in progress.

Learn more biomedcentral.com/submissions 